\title{
ATEELLE
}

\section{"Luz para Todos" na Amazônia: uma reflexão acerca da contribuição do programa para fomentar o desenvolvimento sustentável em Rondônia}

\author{
"Light for All" in The Amazon: a reflection on its \\ contribution to fostering sustainable development in \\ Rondônia
}

\section{"Luz para Todos" en la Amazonía: una reflexión acerca de la contribución a promover el desarrollo sostenible en Rondônia}

\author{
Cristiano Torres do Amaral \\ Faculdade Metropolitana de Rondônia \\ cristiano.amaral@sipam.gov.br \\ Artur de Souza Moret \\ Universidade Federal de Rondônia \\ amoret@unir.br \\ José Manuel Carvalho Marta \\ Universidade Federal de Mato Grosso \\ jmanuelmarta@gmail.com
}

Centro Gestor e Operacional do Sistema de Proteção da Amazônia

\begin{abstract}
Resumo
Texto que apresenta uma reflexão crítica acerca da contribuição do Programa "Luz para Todos" no desenvolvimento sustentável das localidades isoladas da Amazônia, em especial, no estado de Rondônia. Inicialmente são apresentados um breve histórico e os indicadores globais da execução do programa no país. Em seguida, a discussão avança a partir de dados do Estado de Rondônia, avaliando o modelo de geração e distribuição de energia elétrica, bem como analisando a contribuição do programa social para o desenvolvimento sustentável na Região Amazônica. Por fim, as fontes de energia renováveis são sugeridas como alternativa para ampliar o alcance do "Luz para Todos" na Amazônia.
\end{abstract}

Palavras-chave: Luz para Todos, microgrids, sustentabilidade. 


\begin{abstract}
This text shows a reflection about the contribution of the "Light for All" Program to promote sustainable development in the Amazon, especially in the state of Rondônia. Initially, a brief history and overall indicators of program execution in the country are presented. Next, the discussion is based on data from the State of Rondônia, evaluating the model of generation and distribution of electricity, as well as analyzing the contribution of the social program to sustainable development in the Amazon Region. Lastly, renewable energy sources are suggested as an alternative to broadening the scope of the "Light for All" Program in the Amazon.
\end{abstract}

Keywords: Light for All, microgrids, sustainability.

\begin{abstract}
Resumen
El texto que tiene una reflexión sobre la contribución del programa "Luz para Todos" para promover el desarrollo sostenible en la Amazônia brasileña, especialmente en la provincia de Rondônia. Inicialmente se presentan una breve historia y los indicadores globales de la ejecución del programa del país. A continuación, la discusión se mueve desde la provincia de Rondônia datos, la evaluación de la generación y distribución de energía eléctrica modelo, así como el análisis de la contribución del programa social para el desarrollo sostenible de la región amazónica. Por último, las fuentes de energía renovables se sugieren como alternativa para ampliar el alcance de la "Luz para Todos" en la Amazonia.
\end{abstract}

Palabras clave: Luz para Todos, microgrid, sostenibilidad.

\title{
Introdução
}

A universalização da energia elétrica no Brasil sempre foi um desafio para o Estado e a sociedade. Os primeiros programas a difundir a eletrificação em áreas isoladas no país foram o "Luz no Campo", em 1999, administrado pela Eletrobras, e o Programa de Desenvolvimento Energético de Estados e Municípios (PRODEEM). Esses projetos foram direcionados para alcançar as áreas rurais adotando a geração centralizada com uso de energia solar, com o objetivo de alcançar um milhão de consumidores, entretanto, em junho de 2002 , apenas $42 \%$ da meta foi alcançada (BARRETO; DI LASCIO, 2009).

Em novembro de 2003, o Governo Federal lançou o Programa "Luz para Todos" (PLT) com o objetivo de universalizar o acesso à energia elétrica em todo o país. Desde a publicação do Decreto $\mathrm{n}^{\circ} 4.873$, de 11 de novembro de 2003, e a sua prorrogação em 2015 até 2018, o programa já realizou investimentos que ultrapassam 22,7 bilhões de reais. Cerca de 15,5 milhões de pessoas já foram atendidas em todo o país. De acordo com levantamento da Pesquisa Nacional por Amostra de Domicílios (PNAD), houve um incremento de $0,7 \%$ de acesso dos brasileiros à energia elétrica entre 2009 e 2013. Neste levantamento foi apurado que 99,6\% da população tem acesso à energia elétrica e $0,4 \%$, cerca de 800.000 pessoas (exclusão elétrica), ainda não são 
atendidas pela rede de distribuição de eletricidade em todo o país e, na região Norte, o acesso é ainda mais restrito (BRASIL, 2016).

No estado de Rondônia, o PLT teve início em 2005 e, desde a sua implantação, 2.365 famílias foram atendidas. Nesses projetos, o Governo Federal aportou 65\% dos custos, a Centrais Elétricas de Rondônia S.A. (CERON), empresa executora, 25\% e o Governo do Estado de Rondônia com os 10\% restantes. Em abril de 2016, a CERON concluiu o projeto mais recente, na comunidade do Assentamento Capitão Sílvio, em Ariquemes-RO. Nesta localidade, cerca de 140 famílias do assentamento foram atendidas e houve investimento de $\mathrm{R} \$ 1,4$ milhão para construção de uma de rede de distribuição de energia de $30 \mathrm{~km}$. De acordo com estudos da concessionária de energia, no início das atividades do programa, o custo médio de cada unidade consumidora era de $\mathrm{R} \$ 6.100,00$ e já foram investidos mais de $\mathrm{R} \$ 550$ milhões no estado de Rondônia (MACIEL, 2016). Contudo, os dados oficiais são controversos, porque considerando a quantidade de atendimentos divulgada, o custo médio previsto e o montante total investido, a população contemplada deveria ser ainda maior.

David Harvey (2003) é a referência teórica para demonstrar que o processo de implementação da eletricidade obedece à lógica de acumulação excedente. $\mathrm{O}$ procedimento utilizado neste trabalho está baseado na análise de dados do atendimento elétrico no período da implantação do PLT, demonstrando que os resultados do programa não foram suficientes para levar o Desenvolvimento Sustentável da Região. Da mesma forma, a análise de dados demonstrará que o Desenvolvimento Sustentável não foi alcançado porque o modelo de implantação está baseado na reprodução do capital, com modelo de geração de eletricidade baseado em combustíveis fósseis.

Este texto pretende contribuir nessa discussão, destacando a importância do programa, os aspectos relevantes para o desenvolvimento sustentável em Rondônia e a contribuição que o PLT poderia dar neste processo caso tivessem investimentos futuros baseados em conceitos mais eficientes na lógica econômica, ambiental e social.

\section{A importância do "Luz para Todos"}

A universalização da energia elétrica tem por objetivo contribuir para a redução da pobreza e o aumento da renda familiar, uma vez que há correlação entre a falta de eletricidade (exclusão elétrica) e o baixo Índice de Desenvolvimento Humano (IDH) (SLOUGH; URPELAINEN; YANG, 2012). O acesso à energia elétrica pode facilitar a integração de comunidades isoladas aos serviços públicos e aos programas sociais. Também é esperado que seja possível melhorar o abastecimento de água, os serviços de saúde, educação, bem como permitir o acesso aos eletrodomésticos e equipamentos de apoio à produção rural (BRASIL, 2016), que são alguns indicadores de Desenvolvimento Sustentável. Para atender toda a zona rural de Rondônia será necessário alcançar cerca de 48 mil famílias localizadas em áreas isoladas do estado (MOREIRA, 2016; MORET, 2014). 
Outro objetivo do PLT é a geração de empregos utilizando mão de obra local, de maneira que seja possível fomentar o comércio, os serviços e a compra de materiais nos mercados regionais. Essas ações podem favorecer a permanência das pessoas no campo, melhorar a qualidade de vida e estimular os pequenos mercados produtores no campo. No estágio atual, o PLT tenta alcançar as populações localizadas em áreas de vulnerabilidade econômica, tais como comunidades quilombolas, indígenas, assentamentos, ribeirinhos, pequenos agricultores, famílias em reservas extrativistas e populações afetadas por empreendimentos do setor elétrico (BRASIL, 2016). Destaca-se que a referência para o PLT foi a interconexão de polos de geração através de linhas de transmissão, que difere daqueles objetivos de uso de mão de obra local, geração de empregos. Contudo, os custos são altos, porque os atendimentos são distantes e o consumo nem sempre atende os requisitos tradicionais de remuneração da geração de eletricidade.

Na Amazônia, o PLT tem um importante papel, visto que a região é caracterizada pelo difícil acesso e inexpressiva capilaridade da rede de distribuição de energia elétrica. A maior parte da geração e rede distribuição de energia elétrica no país está incluída no Sistema Interligado Nacional (SIN), incluindo parte das cidades de maior porte na Amazônia. As comunidades amazônicas isoladas não são alcançadas por esta infraestrutura, sobretudo as formadas por ribeirinhos, comunidades extrativistas e populações indígenas. Essas famílias não atraem a atenção das empresas concessionárias de distribuição, pois a relação entre o investimento e o retorno financeiro é desvantajosa. Isso significa dizer que são necessários elevados investimentos na construção de linhas de distribuição para atender áreas com baixa densidade populacional - com baixa demanda $\mathrm{kWh}$ per capita.

Em Rondônia é igual e, agravando este cenário, porque o estado tem em sua história programas que incentivaram a ocupação da fronteira e áreas isoladas, longe de todo o tipo de infraestrutura estatal. Inúmeras famílias rondonienses estão localizadas em áreas rurais isoladas desde as décadas de 70/80 e, em pleno século XXI, carecem de acesso aos benefícios da eletricidade, tais como: iluminação pública, meios de comunicação, refrigeração, entre outros serviços disponibilizados (MORET, 2014).

Em função dessas características e particularidades, o PLT tem importância estratégica na região Amazônica, em especial, no estado de Rondônia, porque disponibilizar energia elétrica às comunidades isoladas na Amazônia é proporcionar autonomia e desenvolvimento includente e sustentável (SACHS, 2008).Por outro lado, as dimensões e as áreas isoladas do estado impedem o atendimento tradicional com linhas de transmissão e/ou implantação de sistemas termodiesel de pequeno porte. A Figura 01 apresenta o SIN no Brasil, e a Tabela 1 as comunidades isoladas no estado de Rondônia que são atendidas por sistemas termodiesel de pequeno e médio porte. 


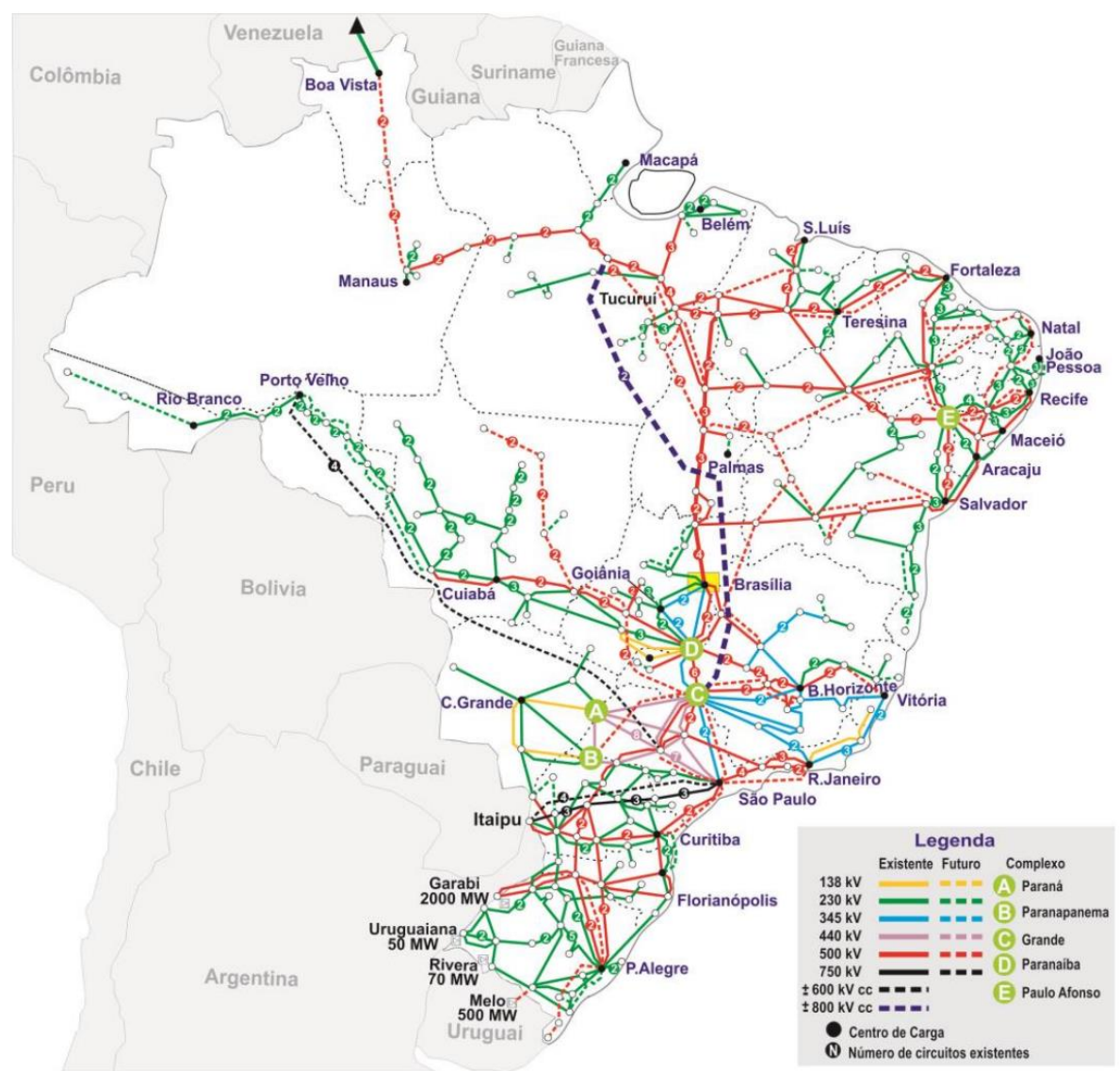

Figura 01. Sistema Interligado Nacional

Fonte: Adaptado de Tolmasquin (2016).

Tabela 01. Localidades com Sistemas Isolados em Rondônia em 2015

\begin{tabular}{c|c|c|c|c|c}
\hline \multirow{2}{*}{ Sistema } & Energia Anual & $\begin{array}{c}\text { Demanda } \\
\text { Máxima Anual }\end{array}$ & $\begin{array}{c}\text { Limite de } \\
\text { Consumo } \\
\text { Específico }\end{array}$ & GT PIE & $\begin{array}{c}\text { Cobertur } \\
\text { a CCC }\end{array}$ \\
\cline { 2 - 6 } $\mathbf{m}^{\mathbf{3}} \mathbf{M W h}$ & $\mathbf{M W h}$ & $\mathbf{m}^{\mathbf{3}}$ \\
\hline Alvorada D'Oeste & 20.688 & 3,616 & 0,283 & & \\
\hline Buritis & 78.289 & 13,957 & 0,253 & & \\
\hline Calama & 2.969 & 0,580 & 0,289 & 648 & 187 \\
\hline $\begin{array}{c}\text { Campo Novo de } \\
\text { Rondônia }\end{array}$ & 9.181 & 1,602 & 0,283 & & \\
\hline
\end{tabular}




\begin{tabular}{|c|c|c|c|c|c|}
\hline \multirow[t]{2}{*}{ Sistema } & Energia Anual & $\begin{array}{c}\text { Demanda } \\
\text { Máxima Anual }\end{array}$ & $\begin{array}{c}\text { Limite de } \\
\text { Consumo } \\
\text { Específico }\end{array}$ & GT PIE & $\begin{array}{c}\text { Cobertur } \\
\text { a CCC }\end{array}$ \\
\hline & MWh & MW & $\mathbf{m}^{3} / \mathbf{M W h}$ & MWh & $\mathbf{m}^{3}$ \\
\hline Costa Marques & 20.887 & 3,705 & 0,283 & & \\
\hline Cujubim & 32.892 & 8,188 & 0,253 & & \\
\hline Demarcação & 301 & 0,120 & 0,349 & 66 & 23 \\
\hline Izidolândia & 1.281 & 0,281 & 0,296 & & \\
\hline Machadinho & 52.099 & 9,316 & 0,253 & & \\
\hline Maici & 35 & 0,011 & 0,404 & 8 & 3 \\
\hline Nazaré & 948 & 0,331 & 0,329 & 223 & 73 \\
\hline Nova Califórnia & 8.912 & 2,676 & 0,283 & & \\
\hline Pacarana & 3.618 & 1,195 & 0,289 & 32 & 11 \\
\hline Pedras Negras & 176 & 0,050 & 0,349 & 192 & 63 \\
\hline $\begin{array}{c}\text { Rolim de Moura } \\
\text { do Guaporé }\end{array}$ & 926 & 0,190 & 0,329 & 62 & 22 \\
\hline Santa Catarina & 282 & 0,062 & 0,349 & 442 & 128 \\
\hline São Carlos & 2.080 & 0,468 & 0,289 & & \\
\hline São Francisco & 35.739 & 7,076 & 0,283 & 240 & 79 \\
\hline Surpresa & 1.045 & 0,221 & 0,329 & & \\
\hline $\begin{array}{c}\text { União } \\
\text { Bandeirantes }\end{array}$ & 13.634 & 3,119 & 0,283 & & \\
\hline Urucumacuã & 1.837 & 0,396 & 0,296 & & \\
\hline Vale do Anari & 13.337 & 2,346 & 0,283 & & \\
\hline Vila Extrema & 13.506 & 2,363 & 0,283 & & \\
\hline $\begin{array}{c}\text { Vista Alegre do } \\
\text { Abunã }\end{array}$ & 20.933 & 5,687 & 0,283 & & \\
\hline Total & 335.685 & 36,4 & 7,607 & 1934 & 598 \\
\hline
\end{tabular}

Fonte: Adaptado de CERON/ELETROBRAS (2015, p. 69).

\section{Breve histórico da eletrificação em Rondônia}

Até o final dos anos 60, o antigo Território Federal do Guaporé tinha o Serviço de Abastecimento de Água Luz e Força (SAALFT) como responsável pelo fornecimento de energia elétrica. Em 1968 foi criada a empresa de economia mista CERON, que passa a exercer o papel do SAALFT. Nos primeiros anos de fornecimento, a rede de geração e distribuição de energia elétrica era baseada apenas em grupos geradores a diesel. Em 1981, no recém-criado Estado de Rondônia, as Centrais Elétricas do Norte do Brasil 
(Eletronorte) assumem o fornecimento de eletricidade para Porto Velho. Em janeiro de 1987, foi inaugurada a primeira Pequena Central Hidrelétrica $(\mathrm{PCH})$ no município de Vilhena. Mesmo assim, o sistema Estadual se manteve apoiado em três formatos de geração: usinas térmicas a diesel, Pequenas Centrais Hidrelétricas (PCHs) e uma Usina Hidrelétrica de 216 MW (instalada no Rio Jamari) que entrou em operação da primeira turbina em julho de 1989. Ao longo dos anos 90, no interior do Estado de Rondônia existiam cerca de 72 usinas térmicas operando em áreas isoladas (MORET, 2014). Atualmente, existem 26 sistemas isolados de geração de energia, minirredes (microgrids) sem conexão ao SIN (FIGURA 02), que atendem cerca de 40 localidades isoladas (ELETROBRAS, 2016) e consomem em torno de 82 milhões de litros de diesel por ano.

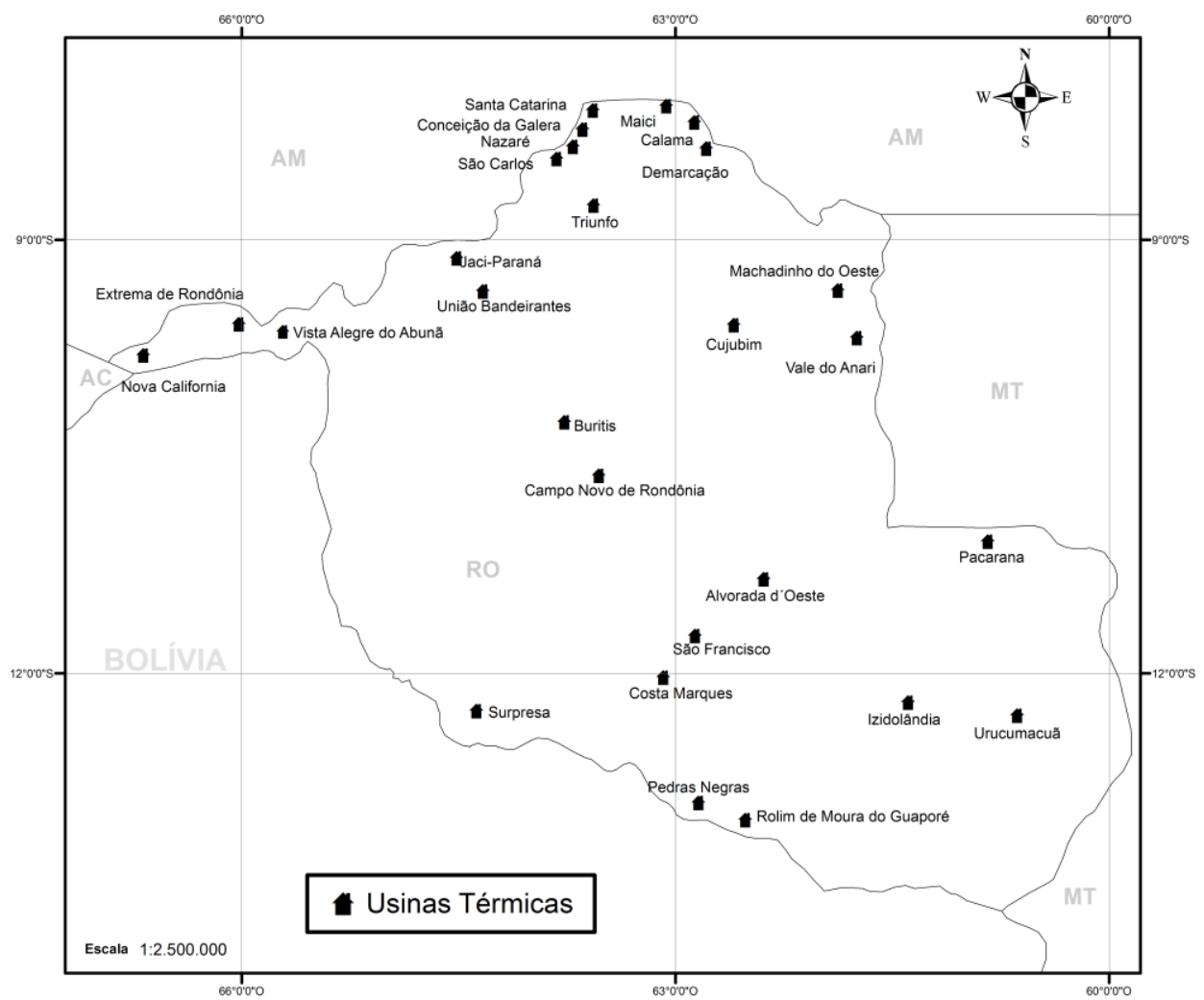

Figura 02. Usinas Térmicas no Estado de Rondônia

Fonte: Adaptado de CERON/ELETROBRAS (2016, p. 70). 


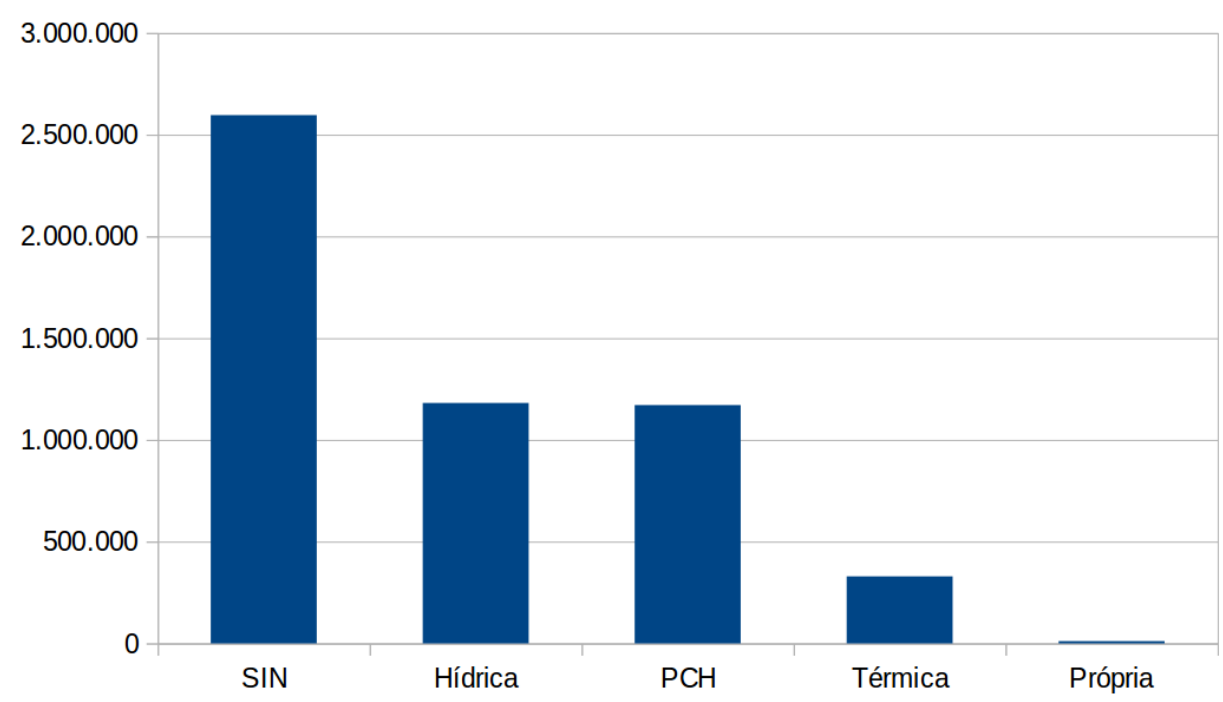

Figura 03. Energia Bruta Requerida em Rondônia (MWh)

Fonte: Adaptado de CERON/ELETROBRAS (2016, p. 69).

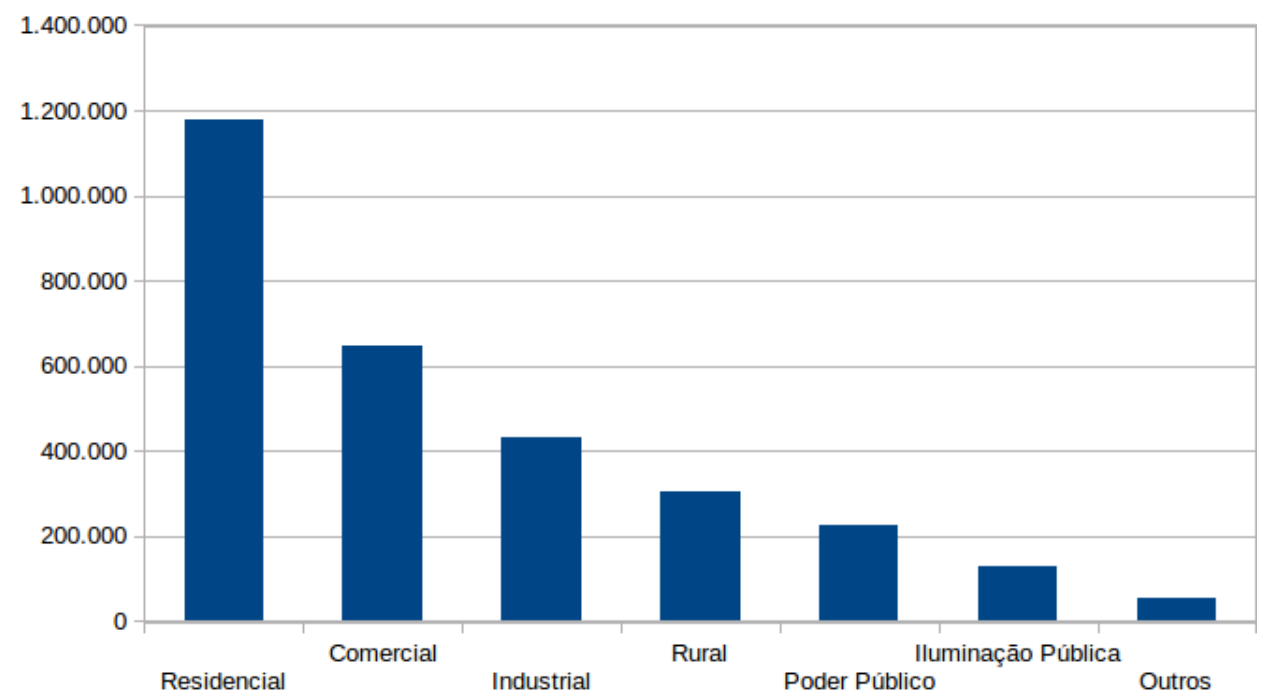

Figura 04. Energia Anual por Classe de Consumo em Rondônia (MWh)

Fonte: Adaptado de CERON/ELETROBRAS (2016, p. 69). 
De acordo com a Agência Nacional de Energia Elétrica (ANEEL), as três grandes usinas de Rondônia (Jirau, Samuel e Santo Antônio) tem capacidade de geração outorgada de 6,7 GW e, conforme observado na Figura 3, grande parte da eletricidade gerada é entregue ao SIN para atender os mercados na região Sul e Sudeste. O sistema isolado abastecido pelas usinas térmicas tem pouca representatividade nesse montante. Entretanto, o segmento residencial e rural dos consumidores possui grande demanda anual no estado (FIGURAS 4 e 5).

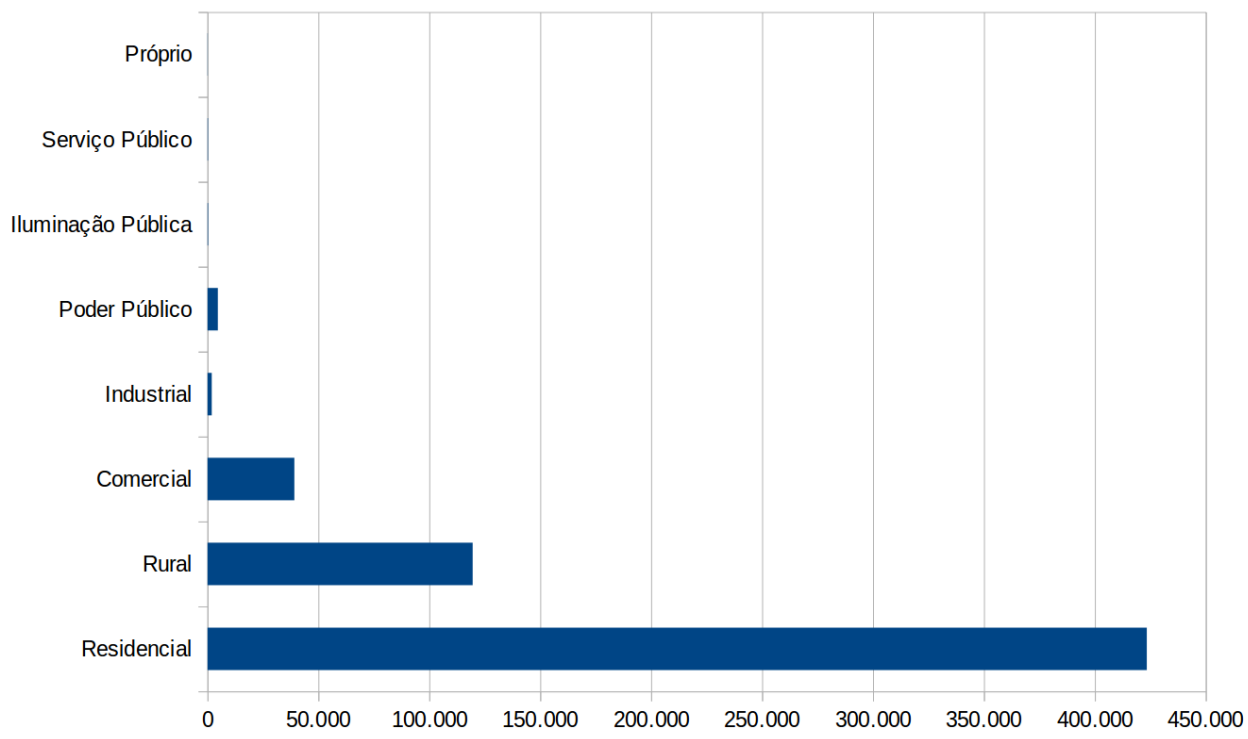

Figura 05. Quantidade de Consumidores em Rondônia. Fonte: Adaptado CERON/ELETROBRAS (2015, p.69).

Os consumidores residenciais e rurais representam o maior número de unidades consumidoras de energia elétrica em Rondônia, bem como a maior demanda por energia. Para esses consumidores deveria haver prioridade de atendimento nos planos de expansão da rede. Entretanto, verifica-se que, ao longo da história recente do estado, os projetos têm priorizado a implantação de energia elétrica para fornecimento ao sistema interligado de Rondônia e posteriormente ao SIN para suprir as demandas dos grandes mercados na região Sudeste. Destaca-se que somente em 2006 o sistema de Rondônia foi interligado ao SIN.

A eletricidade anual consumida por todo o sistema isolado de Rondônia, conforme observado na Tabela 1, alcança o montante de cerca de 335,6 GWh, o que representa apenas $6,2 \%$ do total da energia bruta requerida (FIGURA 3). Por sua vez, a usina hidrelétrica de Santo Antônio, em Porto Velho, tem potência instalada de 3.568 MW e pode gerar até $31,2 \mathrm{TWh}$ funcionando 24 horas por dia em 365 dias do ano. A 
energia anual consumida pelo sistema isolado de Rondônia representa pouco mais de $1,07 \%$ de toda a energia anual gerada em Santo Antônio e poderia facilmente ser suprida pelo parque hidrelétrico instalado. Entretanto, os investimentos em linhas de distribuição são insuficientes para atender essa demanda.

O planejamento de geração e distribuição de energia no estado pode prever investimentos do PLT para alcançar as comunidades isoladas utilizando tecnologias que privilegiem fontes renováveis e a geração descentralizada (BARRETO; DI LASCIO, 2009). Todavia, o modelo atual de geração e distribuição em Rondônia não destaca essa previsão e privilegia a geração centralizada em três grandes usinas hidrelétricas (Samuel, Santo Antônio e Jirau) com a integração de 17 PCHs e 26 Usinas Térmicas (UTE) que consomem cerca de 82,3 milhões de litros de Diesel para geração de 306.001 MWh (ELETROBRAS, 2016).

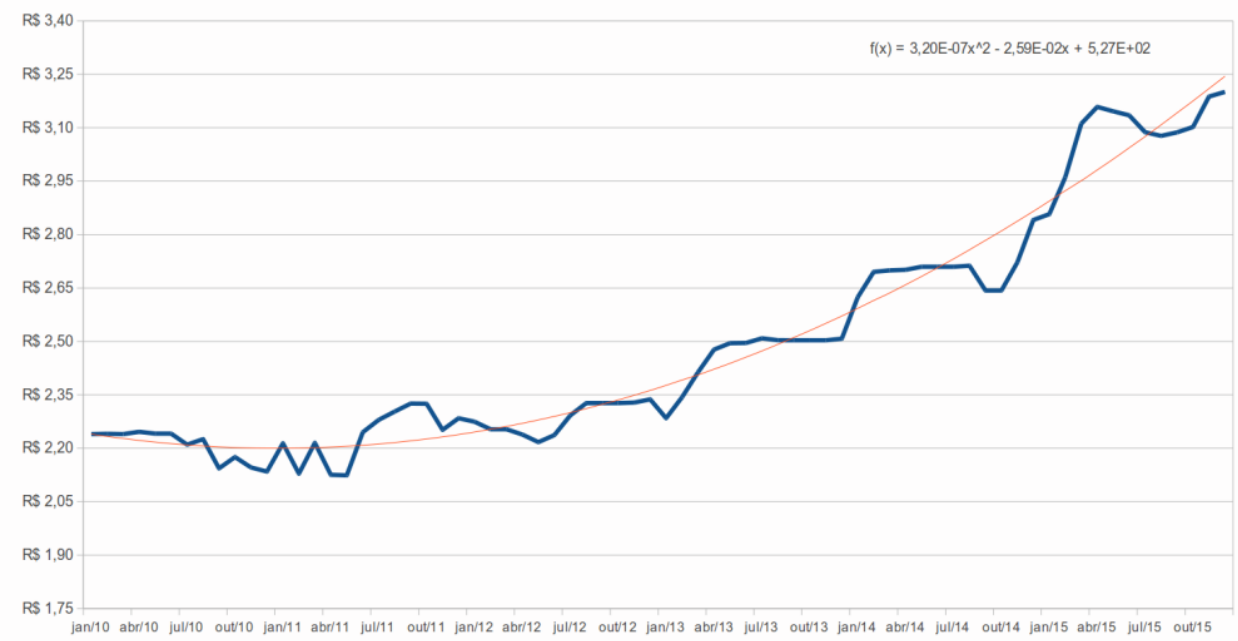

Figura 06. Custo Médio do Diesel para o Setor Elétrico Isolado de Rondônia Fonte: Adaptado dos Relatórios do Grupo Técnico Operacional da Região Norte (ELETROBRAS, 2015).

Por outro lado, há que se destacar que o sistema isolado tem pequenas dimensões, mas a remuneração é atrativa, tanto para as empresas geradoras terceirizadas quanto para os fornecedores de combustível. Em relação ao custo do combustível, a Figura 6 demonstra que o crescimento do custo do diesel para o Setor Isolado de RO entre 2010 e 2015 tem curva de tendência com crescimento quadrático. Não há no mercado uma justificativa aparente para majoração do preço do diesel porque as variáveis que impactam o seu custo (cotação do dólar, transporte, tecnologia de geração) para estas comunidades isoladas não tiveram alterações significativas que promovam esse comportamento. Da mesma forma, inexistem razões para que em 2015 os valores do custo do combustível sejam iguais para todas as comunidades. 


\section{Desenvolvimento Sustentável em Rondônia}

Segundo Harvey (2003, p. 15), o controle da energia (eletricidade, calor e potência) orienta a gestão sobre territórios e contribui para manutenção dos fluxos de poder econômico, transferências monetárias e processos geográficos de acumulação. A lógica do território é apropriada pela lógica do capital. Na Amazônia, e em todo o país, a demanda por energia é determinada pela capacidade de retorno, rentabilidade e pagamento do investimento do setor elétrico (payback).

Nessa perspectiva, o fluxo de capitais tem precedência sobre todos os outros segmentos, isto é, a lógica do capital prevalece sobre os aspectos sociais, culturais, ambientais, etc. As prioridades são orientadas para contribuir com os processos de produção e consumo (HARVEY, 2003, p. 94). Em outras palavras, isso significa dizer que a demanda $\mathrm{kWh}$ per capita nas localidades isoladas é insignificativa economicamente e, ao mesmo tempo, as demandas sociais são ignoradas, pois são irrelevantes para o modelo de consumo e produção capitalista.

Contudo, o Estado pode ser o grande mediador nessa discussão, equilibrando as demandas produtivas, econômicas e socioambientais. Ações como o PLT podem corrigir as desigualdades regionais, fomentar o desenvolvimento local e corrigir as desigualdades regionais na Amazônia. Ou seja, alcançar um desenvolvimento equilibrado, entendendo que a eletricidade é um bem que pode produzi-lo; contudo, a eletricidade sozinha não gera desenvolvimento, mesmo que esse seja um mote para o que é utilizado pelo setor elétrico quando da construção de usinas hidrelétricas (AMARAL; LIMA; GUEDES, 2016).

De acordo com a PNAD (2014), na região Norte do Brasil, 2\% da população carece de acesso a eletricidade. Por outro lado, aquelas localidades isoladas com acesso a eletricidade não tem indicadores de Desenvolvimento Sustentável, porque opera com o diesel, um combustível fóssil, poluente e que contribui para o acúmulo de gases de efeito estufa (GEE). Em contraposição, Moret (2014) demonstrou que o diesel poderia ser substituído pelo óleo vegetal, que é renovável e possui balanço líquido de $\mathrm{CO} 2$ próximo de zero e, sobretudo, porque poderia gerar renda localmente.

O maior obstáculo para o crescimento da economia verde, um dos motes do Desenvolvimento Sustentável, no setor energético, é o modelo de negócio vigente. Segundo Moret (2014), o modelo de negócio adotado pelas concessionárias de energia elétrica é frágil e compromete o desenvolvimento sustentável. $\mathrm{O}$ modelo vigente não prevê o uso de energia renovável e tampouco um sistema descentralizado. Nos sistemas microgrids utilizados em Rondônia (FIGURA 2), padeceu o incentivo a microgeração ou minigeração de fontes alternativas, tais como: solar, eólica, biomassa, biogás, óleos vegetais, microturbinas hidrelétricas. Como síntese do sistema Rondônia temos: duas grandes UHE (Santo Antônio e Jirau) para fornecimento do SIN, uma UHE média que também envia eletricidade para o Acre, um sistema térmico a diesel, PCHs e sistemas pequenos nas localidades isoladas para atender a demanda regional. 
As comunidades isoladas da Amazônia, quilombolas, indígenas, ribeirinhos, pequenos agricultores, famílias em reservas extrativistas e populações afetadas por empreendimentos do setor elétrico não são atores de interesse do capital, ao contrário, na cadeia de produção de energia são encarados como adversários a serem vencidos pelo sistema financeiro (CASTRO-GÓMEZ, 2005).

$\mathrm{O}$ acesso à energia elétrica nas comunidades isoladas, que são aquelas mais vulneráveis da Amazônia, pode facilitar a integração social e econômica delas, bem como melhorar a prestação dos serviços públicos e programas sociais. Este é o grande papel do PLT, uma vez que rompe com o paradigma do desenvolvimento na Amazônia, promovendo o desenvolvimento aproveitando as vocações locais e melhorando as condições de vida dos povos tradicionais. A energia elétrica proporciona o acionamento de dispositivos e equipamentos que podem proporcionar o abastecimento de água de forma regular e segura, funcionamento de eletrodomésticos e recursos que fomentem a produção local e sustentável (BARRETO; DI LASCIO, 2009).

Segundo Castro-Gómez (2005), a natureza não é o grande adversário do homem, por isso não pode ser entendida como um obstáculo a ser vencido pelo setor elétrico. Os ribeirinhos, os povos indígenas e quilombolas não estão em busca de um estágio de desenvolvimento superior, um estilo de vida moderno, ao contrário, buscam a preservação de sua cultura e manutenção de suas famílias na Amazônia. Por isso, o PLT tem um papel fundamental na região, redistribuindo recursos e investimentos de maneira diferenciada, distinta do sistema convencional, alcançando localidades e atores desprezados pela lógica do capital.

\section{Luz para Todos: por uma vida melhor e sustentável}

Para Ribeiro (2008), o desenvolvimento local ou regional é o grande argumento entre os governos e as corporações para justificarem seus investimentos em larga escala. Embora essa justificativa seja atrativa para populações tradicionais, marginais ao desenvolvimento, os interesses e objetivos do setor elétrico privilegiam o crescimento das corporações nacionais ou internacionais, defendendo o capital internacional e transnacional. Os diferentes discursos sobre o potencial de um programa para o desenvolvimento local, regional ou nacional surgem orientados de forma verticalizada, valorizando os fluxos comerciais em detrimento das questões sociais, culturais e ambientais. Por esse motivo, em Rondônia tem se priorizado a implantação de grandes usinas hidrelétricas.

A ideia de Desenvolvimento Sustentável embutida nos programas e projetos governamentais precisa privilegiar a redistribuição de renda e a melhoria da qualidade de vida das comunidades. A política elétrica que sustenta o PLT pode trazer impactos econômicos, tecnológicos, ambientais e sociais significativos, mas para o atual momento será necessário adequações, principalmente no que tange ao uso de combustíveis alternativos e tecnologias de pequena e microgerações. A geração e distribuição de 
energia elétrica no país seguem a racionalidade do capital, da rentabilidade e por isso muitos brasileiros estão desprovidos do acesso à energia elétrica.

A exclusão social e econômica provocada pela ausência de energia elétrica precisa de respostas do Estado. Na Amazônia, esse cenário é agravado pelos conflitos pela preservação dos recursos naturais, culturas tradicionais, povos indígenas e o território de fronteira. As comunidades isoladas, caso queiram ter acesso à energia e aos recursos de financiamento, são obrigadas a aceitar o modelo convencional e centralizado de geração e distribuição de energia elétrica, abdicando de seus interesses, valores e recursos sociais, culturais e ambientais. E ainda, não bastam esses problemas, as comunidades também recebem um número considerável de migrantes com os empreendimentos sem nenhum apoio estatal e causando inúmeros impactos econômicos, sociais e ambientais (RIBEIRO, 1992; MORET, 2014).

Estudos indicam que o modelo convencional de geração e distribuição de energia poderá consumir até oito bilhões de reais para universalização da eletricidade na Amazônia. Conforme observado por Moret (2014) e Sanchez, Torres e Kalid (2015), o subsídio mantido pelo fundo setorial da Conta de Consumo de Combustíveis (CCC) mantém a dependência do diesel como combustível de geração de energia nas áreas isoladas. Esse subsídio foi criado pela Lei Federal $\mathrm{n}^{\circ}$ 5.899/1973 e posteriormente alterado pelas Leis Federais $n^{\circ} 12.111 / 2009$ e $n^{\circ} 12.783 / 2013$. É a CCC que viabiliza o valor das tarifas de distribuição nas áreas isoladas, subsidiando os custos com o consumo diesel (TABELA 1). Assim, constata-se que sem legislação específica que privilegie as fontes de energia limpa e renováveis sempre haverá preferência pela geração e distribuição pelo modelo convencional. Porém, a utilização de combustível alternativo e a descentralização da eletricidade produzem desenvolvimento maior do que as metodologias tradicionais, porque o insumo e a conversão em eletricidade geram renda e fixam o homem no local. Também podemos destacar que os combustíveis renováveis têm subprodutos que podem alterar a realidade de vários locais, como por exemplo, a geração de eletricidade com o uso de óleo de babaçu na Reserva Extrativista (RESEX) do Rio Ouro preto, onde os subprodutos são utilizados para a geração de renda (MORET; BORRERO, 2004).

Outro problema associado ao PLT refere-se ao modelo de execução com concorrências centralizadas no âmbito do programa, o qual estimula acertos e divisão de mercado entre as empresas executoras. Em 2012, o programa foi objeto de análise pelo Tribunal de Contas da União (TCU) para apurar uma possível ocorrência de indícios de conluio entre os licitantes. A análise do órgão regulador identificou algumas estratégias de combinação entre licitantes, as quais comprometiam os custos de execução. Coincidência, ou não, após inúmeras denúncias e maior fiscalização do TCU houve uma notável retração na execução dos investimentos do programa no estado (FIGURA 7). De acordo com o TCU (2012, p. 49): 
Merece destaque o fato de que praticamente não houve competição nos 104 lotes oferecidos, dos quais 81 foram contemplados com, pelo menos, uma proposta de preço válida. Em 79\% das licitações apenas uma proposta válida foi apresentada, e em $11 \%$ foram apenas dois concorrentes qualificados. Nas licitações analisadas o desconto global obtido foi de apenas $2 \%$. Uma concorrência efetiva, via de regra, possibilita a obtenção de maiores descontos globais e a celebração de contratos mais vantajosos para a Administração.

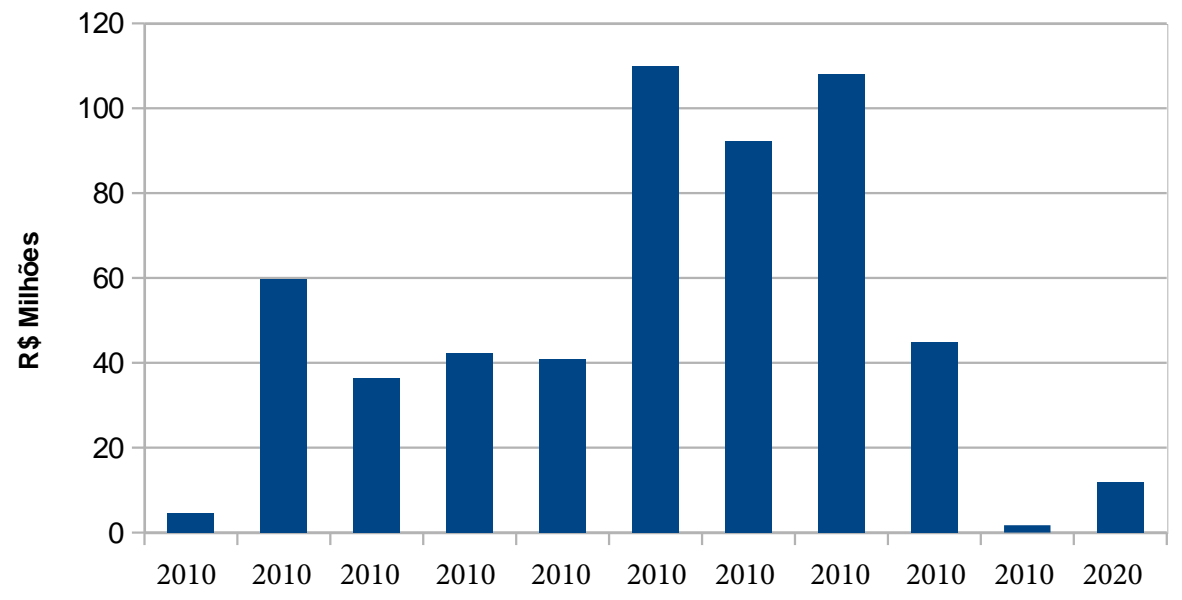

Figura 07. Investimentos do Programa Luz para Todos em Rondônia. Fonte: Adaptado de CERON/ELETROBRAS (2015, p. 67).

Além dos problemas de execução, a estrutura operacional do PLT (FIGURA 08) também está organizada de maneira que não ocorra efetiva participação dos interessados na tomada de decisão, isto é, comunidades de áreas isoladas possuem uma participação tímida no planejamento (MIGLIONI, 1973). Um bom exemplo é a pequena representatividade do Movimento de Atingidos por Barragens, Sindicato dos Engenheiros ou mesmo do Movimento dos Trabalhadores Rurais Sem-Terra nas reuniões do Comitê Gestor Estadual ou Regional. Prevalecem os efeitos da visão empresarial e estatizada nos comitês que definem as prioridades de execução do programa que, em geral, são definidas pelas empresas de energia Eletrobras, Eletronorte e CERON (SOUZA, 2015). 


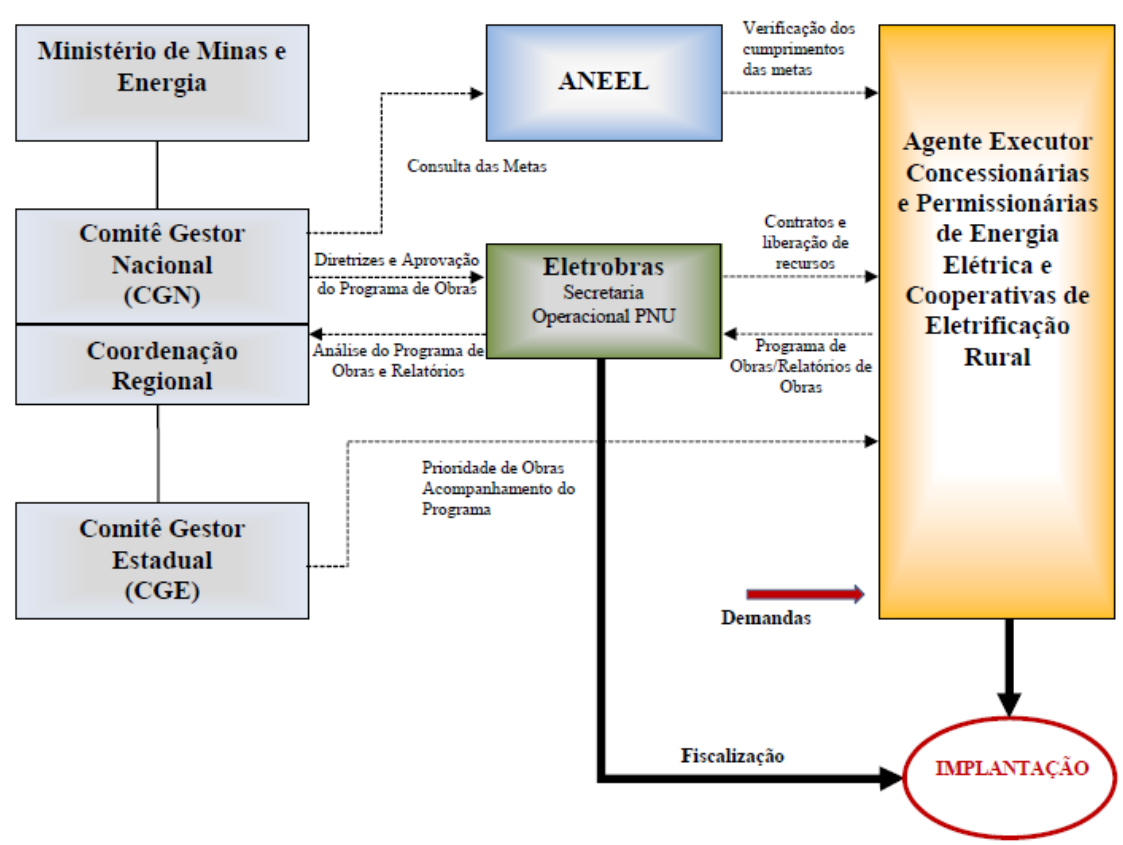

Figura 08. Estrutura Operacional do "Luz para Todos". Fonte: Adaptado de TCU (2012, p .4).

A restrição ao acesso à eletricidade nas comunidades isoladas gera a "exclusão elétrica", que deixa inúmeras famílias amazônicas com uma condição de vida precária e vulnerável. Isso significa dizer que a população carente, que já é obrigada a conviver com a ausência de professores nas escolas públicas, médicos nos postos de saúde e ruas sem pavimentação, também tem que conviver com a falta de refrigeração para guardar a merenda escolar nas escolas e armazenar adequadamente as vacinas nos postos de saúde, e com ruas sem iluminação pública.

Além dos serviços públicos fragilizados, a ausência de energia elétrica em áreas isoladas da Amazônia restringe o acesso das famílias ao conforto diário oferecido pela bomba d'água, uso de ventiladores e refrigeração para acondicionar a produção e a pesca de subsistência. As atividades culturais e sociais também são restritas, posto que as comunidades não possuem áreas apropriadas para realização de confraternizações e festejos com iluminação noturna e sonorização.

A promoção do desenvolvimento territorial na Amazônia passa pela intervenção do Estado com ações em múltiplas escalas. O PLT está atuando em escala local e deve ser integrado com outras ações de governo. Por isso, Bonente e Almeida 
Filho (2008) alertam que qualquer projeto que esteja restrito apenas ao âmbito local está fadado ao fracasso.

Embora a opção convencional seja a única apresentada pelo modelo hegemônico para universalização da energia elétrica, Barreto e Di Lascio (2009) destacam que a geração descentralizada com energias renováveis pode ser um caminho alternativo para superar a dispersão demográfica territorial e a baixa demanda $\mathrm{kWh}$ per capita na Amazônia.

Um bom exemplo de investimento em fontes renováveis é o Projeto Ribeirinhas. Neste projeto do Governo Federal foram utilizadas microgrids com fontes renováveis em áreas remotas da Região Amazônica para eletrificar até 170 domicílios, distribuídos em 27 comunidades. O projeto privilegiava o equilíbrio harmônico entre o homem e a natureza, causando o menor impacto possível com a implantação do sistema. Por isso, é importante fomentar a implantação de sistemas de microgrids associando diferentes fontes de energia (BRASIL, 2016).

O grande desafio no Brasil é fomentar o desenvolvimento sustentável e estimular a economia verde (SMITH et al., 2015). A geração de energia elétrica utilizando combustíveis fósseis para acionamento dos grupos geradores a diesel contribui para emissão de gazes de efeito estufa e por isso não pode ser estimulada em larga escala. A implantação de grandes usinas hidrelétricas compromete o meio ambiente e gera relevantes impactos sociais e ambientais. Por sua vez, as alternativas renováveis não recebem o estímulo adequado para a realidade socioambiental do país, não recebe incentivos fiscais, tributários e linhas de financiamento condizentes com a demanda local, mas são elas que não emitem gazes de efeito estufa, estimulam atividades econômicas com o uso de subprodutos, internalizam renda nas localidades e agregam valor à economia.

Os Estados não podem ignorar as trocas e fluxos desiguais entre as regiões do país e a universalização da energia elétrica pode reduzir essas disparidades e contribuir para o desenvolvimento local (LIMA; SIMÕES, 2010). A energia elétrica é um dos requisitos mínimos para implantação de empreendimentos que possam fomentar a economia local e integrar aos fluxos econômicos regionais. Por esse motivo o PLT tem um papel importante, alterando a lógica financeira para implantação de unidades de geração e distribuição de energia elétrica. É preciso investir localmente com visão global, estruturando o crescimento de maneira sustentável e articulando em âmbito regional.

\section{Considerações finais}

O modelo de geração de eletricidade para os locais isolados da Amazônia não sofreu alteração ao longo dos anos, baseando-se em geração termodiesel, mesmo com a implantação do Programa Luz Para Todos. Esse programa atendeu localidades isoladas a partir da interconexão dos centros de geração já existentes e deixando ainda algumas 
localidades isoladas. Isso ocorreu porque nessas localidades as condições de interligação não são apropriadas para expansão do atendimento seguindo este modelo.

Duas questões são importantes e devem ser destacadas, sendo a primeira na perspectiva do modelo do setor elétrico que não tem aceitação pelos sistemas de geração que utilizam combustíveis alternativos e disponíveis nas localidades isoladas. A segunda é que o diesel utilizado nas localidades isoladas é um combustível que tem na sua cadeia grandes empresas/atores nacionais e multinacionais, detentores do capital, que não tem interesse na perda deste mercado que, mesmo sendo pequeno, é uma importante fonte de recursos. A geração de energia elétrica com usinas termodiesel não fomenta o desenvolvimento nas comunidades porque o combustível é produzido externamente. No caminho inverso, o uso de combustíveis alternativos, disponíveis no local de geração, pode produzir desenvolvimento sustentável para as localidades, porque a renda da produção do combustível fica no local, bem como o uso dos subprodutos que podem ser utilizados para a implantação de atividades econômicas.

Assim, a melhor alternativa para universalização da eletricidade na Amazônia, com o uso do PLP, passa por caminhos que adotem soluções sustentáveis, com visão de futuro e que contemplem as comunidades vulneráveis, para impactar a economia local/regional.

A eletrificação das áreas remotas com recursos energéticos alternativos está relacionada com baixos custos de implantação, harmonização e atenção à natureza, bem como respeito às culturas tradicionais. Apenas a partir de 2015 o Governo Federal declarou as comunidades vulneráveis como prioritárias no PLT. O programa também deixou de fomentar de maneira relevante investimentos na geração distribuída utilizando fontes renováveis. Embora essas limitações do PLT sejam verificadas após 13 anos de implantação, destaca-se a contribuição do programa para melhorar a vida de centenas de famílias na Amazônia.

\section{Referências}

AMARAL, C. T.; LIMA, J. T. G. P.; GUEDES, R. S. Reavaliação da valoração econômica dos recursos ambientais impactados com a usina hidrelétrica de Santo Antônio. Revista Interespaço, v. 2, n. 6, maio/ago. 2016. Disponível em: <http://www.periodicoseletronicos.ufma.br/index.php/interespaco/article/view/6491> Acesso em: 09 mar. 2017.

BARRETO, E. J. F.; DI LASCIO, M. Energia e desenvolvimento sustentável para a Amazônia Rural Brasileira: eletrificação de comunidades isoladas. Brasília: MME, 2009. Disponível em:

<http://jornalggn.com.br/sites/default/files/documentos/solucoes_energeticas_para_a_am azonia.pdf>. Acesso em: 11 fev. 2016. 
BONENTE, B. I.; ALMEIDA FILHO, N. A. Há uma Nova Economia do Desenvolvimento? Revista de Economia, v. 34, n. 1, p. 77-100, jan./abr. 2008. Curitiba: Editora UFPR, 2008.

BRASIL. Ministério de Minas e Energia. Informações sobre o Programa Luz para Todos. Disponível em: <https://www.mme.gov.br/luzparatodos/Asp/o_programa.asp> Acesso em: 31 out. 16.

CASTRO-GÓMEZ, S. Ciências sociais, violência epistêmica e o problema da “invenção do outro". 2005. Disponível em:

$<$ http://bibliotecavirtual.clacso.org.ar/clacso/surur/20100624102434/9_CastroGomez.pdf>. Acesso em: 07 nov. 2016.

CERON/ELETROBRAS. Relatório de Demonstrações Financeiras e Administração 2015. 2016. Disponível em: <http://www.diof.ro.gov.br/data/uploads/2016/04/DOE15_04_2016.pdf>. Acesso em: 29 ago. 2016.

ELETROBRAS. Plano anual de operações dos sistemas isolados para 2016. Grupo Técnico Operacional da Região Norte - GTON. Brasília, DF. 2015. Disponível em: <https://www.eletrobras.com> Acesso em: 02 fev. 2016.

EPE. Empresa de Pesquisa Energética Mapa do Sistema Interligado Nacional com PDE 2024. Disponível em:

<http://www.epe.gov.br/Transmissao/Documents/MapaSIN_EPE_2015.pdf>. Acesso em: 05 set. 2016.

GOMEZ, M. F.; SILVEIRA, S. Delivering off-grid electricity systems in the Brazilian Amazon. 2012. Disponível em:

<http://www.sciencedirect.com/science/article/pii/S0973082612000099>. Acesso em: 29 ago. 2016.

HARVEY, D. O novo imperialismo. São Paulo: Ed. Loyola, 2003.

IBGE. Instituto Brasileiro de Geografia e Estatística. Pesquisa Nacional por Amostra de Domicílios (PNAD: síntese dos indicadores. 2014. Disponível em:

<http://biblioteca.ibge.gov.br/visualizacao/livros/liv94935.pdf>. Acesso em: 13 mar. 2017.

LIMA, A. C. C.; SIMÕES, R. F. Teorias clássicas do desenvolvimento regional e suas implicações de política econômica: o caso Brasil. Revista de Desenvolvimento Econômico, ano XII, n. 21. Jul. 2010.

MACIEL, F. CERON: o início efetivo do Luz para Todos. Disponível em: $<$ http://www.gentedeopiniao.com.br/mobile/noticia/ceron-o-inicio-efetivo-do-luz-paratodos/5974 >. Acesso em: 16 nov. 2016. 
MOREIRA, R. Programa Luz para Todos avança em Rondônia. Disponível em: $<$ http://www.gentedeopiniao.com.br/mobile/energia/noticia/programa-luz-para-todosavanca-em-rondonia/151658>. Acesso em: 16 nov. 2016.

MORET, A. S. (Org.). Rondônia: 2000-2013. São Paulo: Editora Fundação Perseu Abramo, 2014.

MORET, A. S.; BORRERO, M. A. V. A Implantação de Modelo Sustentável de Produção de Energia Elétrica a Partir do Óleo de Babaçu: A Experiência de Resex RioOuro Preto/Guajará Mirim/RO. In: CONGRESSO BRASILEIRO DE ENERGIA, 10., 2004. Rio de Janeiro. Anais... Rio de Janeiro: COPPE/UFRJ, 2004. Disponível em: <http://www.ppe.ufrj.br/xcbe/cbettec.htm> Acesso: em 09 mar. 17.

RIBEIRO, G. L. Bichos de obras: fragmentação e reconstrução de identidade. Revista Brasileira de Ciências Sociais, Rio de Janeiro, v. 18, 1992.

RIBEIRO, G. L. Poder, Redes e Ideologia no campo do desenvolvimento. Novos Estudos, n. 80, mar. 2008. Disponível em:

<http://www.scielo.br/pdf/nec/n80/a08n80.pdf> Acesso em: 09 nov. 2016.

SANCHEZ, A.; TORRES, E.; KALID, R. Renewable energy generation for the rural electrification of isolated communities in the Amazon Region. 2015. Disponível em: <http://www.sciencedirect.com/science/article/pii/S1364032115003457> Acesso em: 29 ago. 2016.

SLOUGH, T.; URPELAINEN, J.; YANG, J. Light for all? Evaluating Brazil's rural electrification progress 2000-2010. 2012. Disponível em:

<http://www.sciencedirect.com/science/article/pii/S0301421515300124>. Acesso em: 29 nov. 2016.

SMITH, C. et al. Comparative Life Cycle Assessment of a Thai Island's diesel/PV/wind hybrid microgrid. 2015. Disponível em:

<http://www.sciencedirect.com/science/article/pii/S0960148115000105>. Acesso em: 29 ago. 2016.

SOUZA, M. M. Políticas de energia e desenvolvimento regional: uma análise sobre as disputas em torno do Programa Luz Para Todos em Rondônia. 2015. 114 f. Dissertação (Mestrado em Desenvolvimento Regional e Meio Ambiente) - Programa de PósGraduação em Desenvolvimento Regional e Meio Ambiente, Fundação Universidade Federal de Rondônia, Porto Velho, 2015.

TOLMASQUIN, M. T. Energia renovável: hidráulica, biomassa, eólica, solar, oceânica. 2016. Disponível em: < http://www.epe.gov.br/Documents/Energia\%20Renov\%C3\%A1vel\%20\%20Online\%2016maio2016.pdf> Acesso em: 09 mar. 2017. 


\section{Cristiano Torres do Amaral}

Doutorando em Desenvolvimento Regional e Meio Ambiente pela Fundação Universidade de Rondônia. Mestre em Geografia e em Engenharia Elétrica pela Universidade Federal de Minas Gerais. Graduado em Geografia pela mesma instituição. Graduado em Engenharia de Telecomunicações pelo Centro Universitário de Belo Horizonte. Atualmente é analista de ciência e tecnologia do Centro Gestor e Operacional do Sistema de Proteção da Amazônia e Coordenador do Curso de Engenharia Elétrica da Faculdade Metropolitana.

Rua Avenida Lauro Sodré, 6500 - Aeroporto, Porto Velho- RO, CEP: 76.803-260.

E-mail: cristiano.amaral@sipam.gov.br

\section{Artur de Souza Moret}

Doutor em Planejamento de Sistemas Energéticos pela Universidade Estadual de Campinas. Mestre em Ensino de Ciências pela Universidade de São Paulo. Graduado em Física pela Universidade Federal Fluminense. Atualmente é professor do Programa de Pós-Graduação em Desenvolvimento Regional e Meio Ambiente da Fundação Universidade Federal de Rondônia, em níveis de Mestrado e Doutorado.

BR 364 Km 9,5, Porto Velho - RO, CEP: 76800-000.

E-mail: amoret@unir.br

\section{José Manuel Carvalho Marta}

Doutor em Planejamento de Sistemas Energéticos pela Universidade Estadual de Campinas. Bacharel em Economia pela Universidade Federal de Mato Grosso. Atualmente é professor aposentado associado II da Faculdade de Economia da Universidade Federal de Mato Grosso e professor visitante do Programa de PósGraduação em Desenvolvimento Regional e Meio Ambiente da Fundação Universidade Federal de Rondônia.

BR 364 Km 9,5, Porto Velho - RO, CEP: 76800-000.

E-mail: jmanuelmarta@gmail.com 